\title{
Cancer mortality and quantitative oil production in the Amazon region of Ecuador, 1990-2010
}

\author{
Suresh H. Moolgavkar • Ellen T. Chang • \\ Heather Watson • Edmund C. Lau
}

Received: 22 May 2013/Accepted: 11 October 2013/Published online: 30 November 2013

(C) The Author(s) 2013. This article is published with open access at Springerlink.com

\begin{abstract}
Purpose Controversy persists over whether cancer risk is increased in communities surrounding oil fields, especially in the Oriente region of Ecuador. This ecologic study uses quantitative exposure data, updated mortality data, and improved statistical methods to study the impact of oil exploration and production activities on cancer mortality rates in the Oriente.

Methods Cancer mortality rates in the Oriente in 1990 through 2010 were compared between seven cantons with active oil exploration and production as of 1990 and thirteen cantons with little or no such activities. Poisson regression was used to estimate mortality rate ratios (RRs) adjusted for age and sex. In a two-stage analysis, cantonspecific log-RRs were regressed against quantitative estimates of cumulative barrels of oil produced and well-years per canton, adjusting for canton-level demographic and socioeconomic factors.

Results Overall and site-specific cancer mortality rates were comparable between oil-producing and non-oil-producing cantons. For overall cancer mortality in males and females combined, the RR comparing oil-producing to non-oil-producing cantons was 0.85 [95\% confidence interval (CI) 0.72-1.00]. For leukemia mortality, the
\end{abstract}

Electronic supplementary material The online version of this article (doi:10.1007/s10552-013-0308-8) contains supplementary material, which is available to authorized users.

S. H. Moolgavkar $(\bowtie) \cdot$ E. T. Chang · E. C. Lau Health Sciences Practice, Exponent, Inc., 149 Commonwealth Drive, Menlo Park, CA 94025, USA

e-mail: moolgavkar@gmail.com

H. Watson

Statistical and Data Sciences Practice, Exponent, Inc., 149

Commonwealth Drive, Menlo Park, CA 94025, USA corresponding RR was 0.80 (95\% CI 0.57-1.13). Results also revealed no excess of mortality from acute non-lymphocytic, myeloid, or childhood leukemia. Standardized mortality ratios were consistent with RRs. Canton-specific RRs showed no pattern in relation to oil production volume or well-years.

Conclusions Results from this first ecologic study to incorporate quantitative measures of oil exploration and production showed no association between the extent of these activities and cancer mortality, including from cancers associated with benzene exposure.

Keywords Cancer - Ecuador - Epidemiology ·

Leukemia $\cdot$ Mortality $\cdot$ Petroleum

\section{Introduction}

Little is known about the potential adverse human health impact of oil exploration and production on surrounding communities. In 1989, the International Agency for Research on Cancer (IARC) [1] determined that crude oil is "not classifiable as to its carcinogenicity in humans," based on "inadequate evidence" for carcinogenicity in humans and "limited evidence" for carcinogenicity in experimental animals. However, questions persist about the health impact of oil exploration and production on surrounding communities. One reason for the paucity of knowledge about the potential environmental health effects of oil production is the difficulty of studying this issue rigorously. Any community health impact of oil production is not readily disentangled from the potential effects of socioeconomic status, sanitation, nutrition, health care access, lifestyle, and other health-related factors that may differ between areas with and without oil fields. 
Furthermore, many regions with oil fields lack high-quality, population-based data on disease incidence and/or mortality, as well as relevant data on exposure to crude oil or oil-related activities.

To date, the few studies of cancer incidence or mortality in communities with oil exploration and production activities have been ecologic in design and most have been based in the Amazon region of Ecuador, where oil extraction has taken place since 1972. Hurtig and San Sebastián [2] reported excesses in the incidence of overall and several site-specific cancers in four oil-producing cantons, compared with eleven non-oil-producing cantons, in this region in 1985-1998. Incident leukemias, but not other cancers, were also reported to be significantly more common among children in oil-producing cantons [3]. However, in an alternative analysis using cancer mortality data from the same region, Kelsh et al. [4] found no evidence that death from these cancers, or cancer overall, was higher in long-term oil-producing than non-oil-producing cantons. Combined with concerns about data quality and availability, exposure assessment, case ascertainment, population estimation, interpretation of results, and study reproducibility [5, 6], the inconsistent cancer incidence and mortality results have failed to resolve the question of whether oil production activities increase the risk of cancer in local populations.

To date, no epidemiologic studies of cancer in communities surrounding oil exploration and production activities have used quantitative information on oil-related activities. Rather, previous studies have broadly classified geographic regions as either active or not active in oil exploration and production, thereby ignoring any variation in the level of activity. To enhance prior findings by capturing the extent of oil-related activities more precisely, we sought to incorporate canton-level data on oil well locations and oil production volumes. In addition, we extended prior studies by using a more flexible and detailed statistical approach, additional years of mortality and population data, and supplemental population data on socioeconomic status, ethnicity, health care access, and residential mobility, to more thoroughly examine cancer mortality in regions with different levels of oil exploration and production activity in the Ecuadorian Amazon region.

\section{Methods}

\section{Population data}

Most oil exploration and production activity in Ecuador is found in the Oriente (East) region within Napo, Pastaza, Orellana, and Sucumbíos Provinces. The population and mortality data of these four provinces from 1990 through 2010 are analyzed in this study.

Population counts for cantons in the Oriente provinces in 1990, 2001, and 2010 were obtained from the Ecuador National Census (www.inec.gov.ec) [7, 8]. We also used the 2001 and 2010 census data on residential locations 5 years previously to estimate population counts in 1996 and 2005. To estimate intercensal population counts, we interpolated between the population counts in 1990, 1996, 2001, 2005, and 2010 by using a Poisson regression model that included 5-year age group, sex, year, and age-sex, age-year, and sex-year interactions to account for age- and sex-specific trends in population growth. The expected population, $P_{i j}$, in the $i$ th age group and $j$ th sex group in each canton was estimated by the following Poisson model:

$$
\begin{aligned}
E\left(P_{i j}\right)= & \mathrm{Age}_{i} \times \mathrm{Sex}_{j} \times \text { Year } \times\left(\mathrm{Age}_{i} \mathrm{Sex}_{j}\right) \times\left(\mathrm{Age}_{i} \text { Year }\right) \\
& \times\left(\mathrm{Sex}_{j} \text { Year }\right)
\end{aligned}
$$

Because Ecuador's administrative divisions have changed in the past 30 years, statistical adjustments to the census and mortality data were made to conform to the administrative divisions in 2010 (Supplementary Table 1).

Mortality data

Annual mortality data from 1990 through 2010 were obtained from the Ecuador National Census. We examined all cancer-related mortality and 25 site-specific cancer causes of death (Supplementary Table 2), including leukemia, childhood leukemia (ages $<15$ years at diagnosis), acute non-lymphocytic leukemia (ANLL), and acute myeloid leukemia (AML, which comprised $83 \%$ of ANLL). Death rates were analyzed based on the canton of residence at the time of death. Foreign residents who died in Ecuador were excluded. Records with missing age $(0.25 \%)$ or without a valid code for province/canton $(0.06 \%)$ were also excluded.

Oil well and oil production data

To quantify the association between mortality and canton-level oil exploration and production activities, we obtained information on oil wells and oil fields from Empresa Pública Petroecuador (www.eppetroecuador.ec/ide/ groups/public/documents/archivo/001373.pdf and www. eppetroecuador.ec/idc/groups/public/documents/archivo/ 001375.pdf). The locations of these wells and fields were overlaid on the province-canton boundaries to quantify oil exploration and production in each canton (Fig. 1). We calculated "well-year" as a measure of the cumulative number of oil wells and total years of existence within each canton (Table 1). For a more direct quantification of oil 
Fig. 1 Ecuador's northern Amazon provinces, showing oil wells, oil fields, and "bloque" areas overlaid on province and canton boundaries

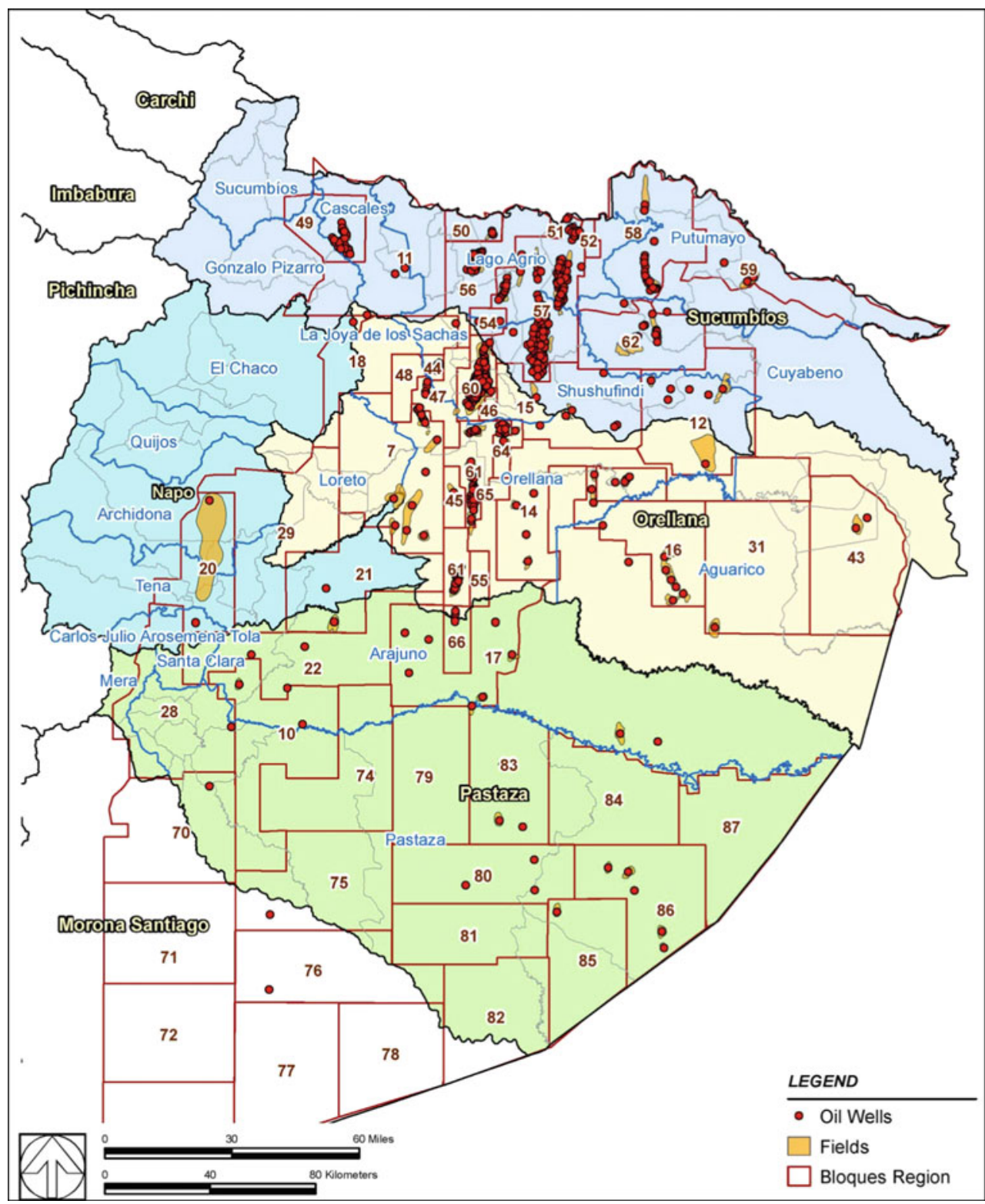

production activity in a given canton, we compiled the total volume of oil produced from 1972 to 2011 based on Petroecuador's annual reports of oil production $[9,10]$.

Oil production volume was reported at the level of the oil field or "bloque" (i.e., geographic area designated for oil exploration and production). When an oil field or bloque crossed over canton boundaries, production data were divided proportionally based on the number of wells within each canton. The cumulative number of well-years and the total amount of oil produced from 1972 to 1990 were used to quantify oil exploration and production in each canton. Alternative cutoff dates were evaluated in sensitivity analyses. Seven cantons in the four provinces had a history of oil exploration and production activities as of 1990, whereas thirteen cantons had little or no oil-related activity (Table 1).

Statistical analysis

Comparisons of overall and site-specific cancer mortality between the seven oil-producing cantons and the thirteen non-oil-producing cantons were conducted using both Poisson regression and indirect standardization. Following the age-cohort method proposed by Breslow and Day [11, 12], we used Poisson regression to model overall and sitespecific cancer mortality rates as a function of age, sex, and canton-level oil exploration and production activities. The expected number of deaths, $D_{i j k}$, was calculated from the 
Table 1 Cumulative number of barrels of oil produced (in thousands), wells, and well-years by canton in the northern Amazon provinces of Ecuador, 1990, 2000, and 2010

\begin{tabular}{|c|c|c|c|c|c|c|c|c|c|c|}
\hline \multirow[t]{2}{*}{ Province and Canton } & \multicolumn{3}{|l|}{1990} & \multicolumn{3}{|l|}{2000} & \multicolumn{3}{|l|}{2010} & \multirow{2}{*}{$\begin{array}{l}\text { Oil-Related } \\
\text { Activity as } \\
\text { of } 1990\end{array}$} \\
\hline & Oil Production & Wells & Well-Years & Oil Production & Wells & Well-Years & Oil Production & Wells & Well-Years & \\
\hline \multicolumn{11}{|l|}{ Napo } \\
\hline Tena & 0 & 2 & 22 & 641 & 7 & 56 & 31,357 & 62 & 417 & Inactive \\
\hline Archidona & 0 & 1 & 11 & 0 & 1 & 21 & 0 & 2 & 32 & Inactive \\
\hline El Chaco & 0 & 1 & 19 & 0 & 1 & 29 & 0 & 1 & 39 & Inactive \\
\hline Quijos & 0 & 0 & 0 & 0 & 0 & 0 & 0 & 0 & 0 & Inactive \\
\hline $\begin{array}{l}\text { Carlos Julio } \\
\text { Arosemena Tola }\end{array}$ & 0 & 1 & 18 & 0 & 1 & 28 & 0 & 1 & 38 & Inactive \\
\hline Napo Total & 0 & 5 & 70 & 641 & 10 & 134 & 31,357 & 66 & 526 & \\
\hline \multicolumn{11}{|l|}{ Pastaza } \\
\hline Pastaza & 0 & 21 & 216 & 8,049 & 22 & 436 & 28,837 & 22 & 656 & Inactive \\
\hline Mera & 0 & 0 & 0 & 0 & 0 & 0 & 0 & 0 & 0 & Inactive \\
\hline Santa Clara & 0 & 0 & 0 & 0 & 0 & 0 & 0 & 0 & 0 & Inactive \\
\hline Arajuno & 422 & 17 & 264 & 8,562 & 33 & 485 & 113,103 & 54 & 952 & Inactive \\
\hline Pastaza total & 422 & 38 & 480 & 16,611 & 55 & 921 & 141,940 & 76 & 1,608 & \\
\hline \multicolumn{11}{|l|}{ Sucumbíos } \\
\hline Lago Agrio & 259,180 & 151 & 1,494 & 500,588 & 207 & 3,376 & 649,561 & 276 & 5,719 & Active \\
\hline Gonzalo Pizarro & 0 & 0 & 0 & 0 & 0 & 0 & 0 & 0 & 0 & Inactive \\
\hline Putumayo & 18,725 & 37 & 273 & 70,817 & 59 & 763 & 140,856 & 103 & 1,538 & Active \\
\hline Shushufindi & 644,747 & 106 & 1,601 & $1,038,094$ & 175 & 3,107 & $1,307,258$ & 298 & 5,329 & Active \\
\hline Sucumbíos & 0 & 0 & 0 & 0 & 0 & 0 & 0 & 0 & 0 & Inactive \\
\hline Cascales & 9,846 & 36 & 341 & 26,802 & 51 & 795 & 50,754 & 75 & 1,469 & Active \\
\hline Cuyabeno & 20,180 & 21 & 301 & 70,180 & 81 & 676 & 232,904 & 301 & 2,844 & Active \\
\hline Sucumbíos Total & 952,678 & 351 & 4,010 & $1,706,481$ & 573 & 8,717 & $2,381,333$ & 1,053 & 16,899 & \\
\hline \multicolumn{11}{|l|}{ Orellana } \\
\hline Francisco de Orellana & 141,668 & 100 & 1,051 & 488,381 & 264 & 3,165 & 997,553 & 603 & 7,478 & Active \\
\hline Aguarico & 0 & 12 & 129 & 102,281 & 74 & 533 & 363,587 & 200 & 2,002 & Inactive \\
\hline Joya de los Sachas & 405,845 & 124 & 1,866 & 622,977 & 181 & 3,427 & $1,039,290$ & 334 & 5,918 & Active \\
\hline Loreto & 0 & 0 & 0 & 0 & 2 & 5 & 221 & 7 & 36 & Inactive \\
\hline Orellana Total & 547,513 & 236 & 3,046 & $1,213,640$ & 521 & 7,130 & $2,400,651$ & 1,144 & 15,434 & \\
\hline
\end{tabular}

multiplicative contributions of the $i$ th age group (with ages $<35$ years combined for some analyses), the $j$ th sex group, the activity level of the $k$ th canton, and the age-, sex-, and canton-specific person-years, $P Y_{i j k}$, and was estimated by the following Poisson model:

$E\left(D_{i j k}\right)=\operatorname{Age}_{i} \times \operatorname{Sex}_{j} \times$ Oil Activity $_{k} \times P Y_{i j k}$.

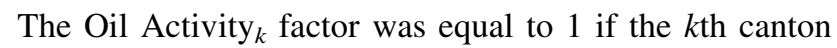
was active in oil exploration and production, and 0 otherwise. The parameter associated with this factor provided an estimate of the mortality rate ratio (RR) comparing oilproducing with non-oil-producing cantons.

For comparability to prior publications that reported standardized incidence and mortality ratios [2-4], we used the indirect standardization method to estimate standardized mortality ratios (SMRs) comparing the observed with the expected number of deaths in the seven oil-producing cantons. The expected number of deaths was calculated using age- and sex-specific mortality rates from the thirteen non-oil-producing cantons and applying those rates to the person-years from the seven oil-producing cantons. For SMR analyses including males and females, the expected number of deaths was calculated as follows:

Expected $=\sum_{i j} R_{i j} \times P Y_{i j}$

where $R_{i j}$ was the mortality rate for the $i$ th five-year age group and $j$ th sex group in non-oil-producing cantons, and $P Y_{i j}$ was the corresponding age- and sex-specific personyears in oil-producing cantons. In SMR analyses of males and females considered separately, the expected number of deaths was summed over age-specific mortality rates and the corresponding age-specific person-years for each sex. We used the method suggested by Rothman and Boice [13] to estimate confidence intervals (CIs) and associated $p$ values for the SMRs.

To further understand the variation in cancer mortality rates among the study cantons, the Poisson model was used 
to estimate cancer-specific mortality RRs for each of the 20 cantons, without designating particular cantons as active or inactive in oil exploration and production. We used Lago Agrio Canton in Sucumbíos Province as the reference because it had the largest population in the study area; use of a different reference group would not affect the overall results. Scatterplots were created to examine the patterns of association between the RR estimates and oil production metrics, with a nonparametric Loess regression line added to facilitate detection of any trends. To estimate the strength of association more quantitatively, we treated the Poisson regression as the first stage in the regression analysis and, as a second stage, regressed the canton-specific Poisson log-RRs as the dependent variable against cantonlevel oil production volume, well-years, and censusderived data on the proportion of adults who had completed high school, indigenous fraction in the population, availability of health care facilities per capita, and residential mobility in the previous 5 years. Although oil exploration and production began in the 1970s in many areas, we performed sensitivity analyses allowing for an additional 10-year induction period by relating oil production volume or well-years as of 1990 to cancer mortality in 2000-2010.

Statistical analyses were performed with SAS v9.3.

\section{Results}

Demographic characteristics and cancer mortality rates of populations residing in the four northern Amazon provinces are summarized in Supplementary Tables 3 and 4. Results from the Poisson regression analysis of cancer mortality in oil-producing versus non-oil-producing cantons among males and females analyzed together and separately are shown in Fig. 2. The corresponding numerical results from both the Poisson regression and SMR analyses are shown in Table 2. For males and females combined, the RR for all cancer-related deaths was 0.85 (95\% CI 0.72-1.00) comparing the seven oil-producing cantons with the thirteen non-oil-producing cantons. When males and females were analyzed separately, the RRs showed a similar deficit. We found few consistent elevations in the mortality rate of any site-specific cancer in oil-producing versus non-oil-producing cantons based on either RRs or SMRs in males and females together or separately. Ten or fewer deaths were identified in the oilproducing cantons for each of the following cancers, resulting in imprecise RR estimates: lip/mouth/pharynx (the only cancer for which RR estimates were $>1.0$ in males, females, and both sexes combined), testis, skin, thyroid, kidney, bladder, and multiple myeloma.

Mortality from leukemia was not elevated in oil-producing compared with non-oil-producing cantons (Fig. 2).
Likewise, mortality from ANLL or AML was not higher in cantons that were active in oil exploration and production, although results were based on small numbers of deaths. Leukemia-related mortality among children up to age 14 years also was not associated with the presence of oilrelated activities. Of all the specific cancer sites examined, only mortality from cancer of the lip, mouth, and pharynx was elevated among both males and females in the oilproducing cantons, but estimates were statistically unstable. Classification of canton-level oil production status according to the system used by [2] yielded no substantial difference (data not shown).

The 20 canton-specific RRs from the Poisson regression analysis of overall and site-specific cancer mortality (with Lago Agrio as the reference, $R R=1$ ), adjusted for age and sex, are shown in Fig. 3. The figure reveals no apparent association between oil-related activity in each canton and the RRs for mortality from overall cancer, overall leukemia, childhood leukemia, ANLL, AML, or lymphoma. Rank-ordering of the RRs showed no apparent patterns to suggest increased RRs in the oil-producing cantons. Among the oil-producing cantons, the magnitude of the RR bore no relationship with the amount of oil produced, as represented by the size of the markers in Fig. 3. Due to sparse numbers for AML and ANLL, RRs could not be estimated in some cantons with insufficient data. Scatterplots of the RRs for mortality from overall cancer and other major cancer sites against total volume of oil produced or total well-years also showed no consistent differences in cancer mortality according to level of oil production activity (Fig. 4).

To further examine the association between cancer mortality and the extent of oil exploration and production activities, the age- and sex-adjusted canton-specific logRRs were regressed against canton-level barrels of oil produced (per 100 million) and well-years (per 1,000) as of 1990, 2000, and 2010, with or without adjustment for educational attainment, indigenous fraction, and health care facilities per capita. Residential mobility was not associated with overall or site-specific cancer mortality and therefore was not included. After multivariate adjustment, no consistent, stable positive associations were observed between the two metrics of oil production and exploration activities and site-specific cancer mortality rates (Table 3). When the analysis was not adjusted for canton-level educational attainment, indigenous fraction, or health care facilities (data not shown), most of the results were not meaningfully different. Well-years but not oil production was positively associated with mortality from cancer of the lip, mouth, and pharynx, whereas inverse associations were detected with mortality from multiple myeloma and cancers of the pancreas, testis, thyroid, and bladder and other urinary organs. Sensitivity analyses allowing for a 10-year 


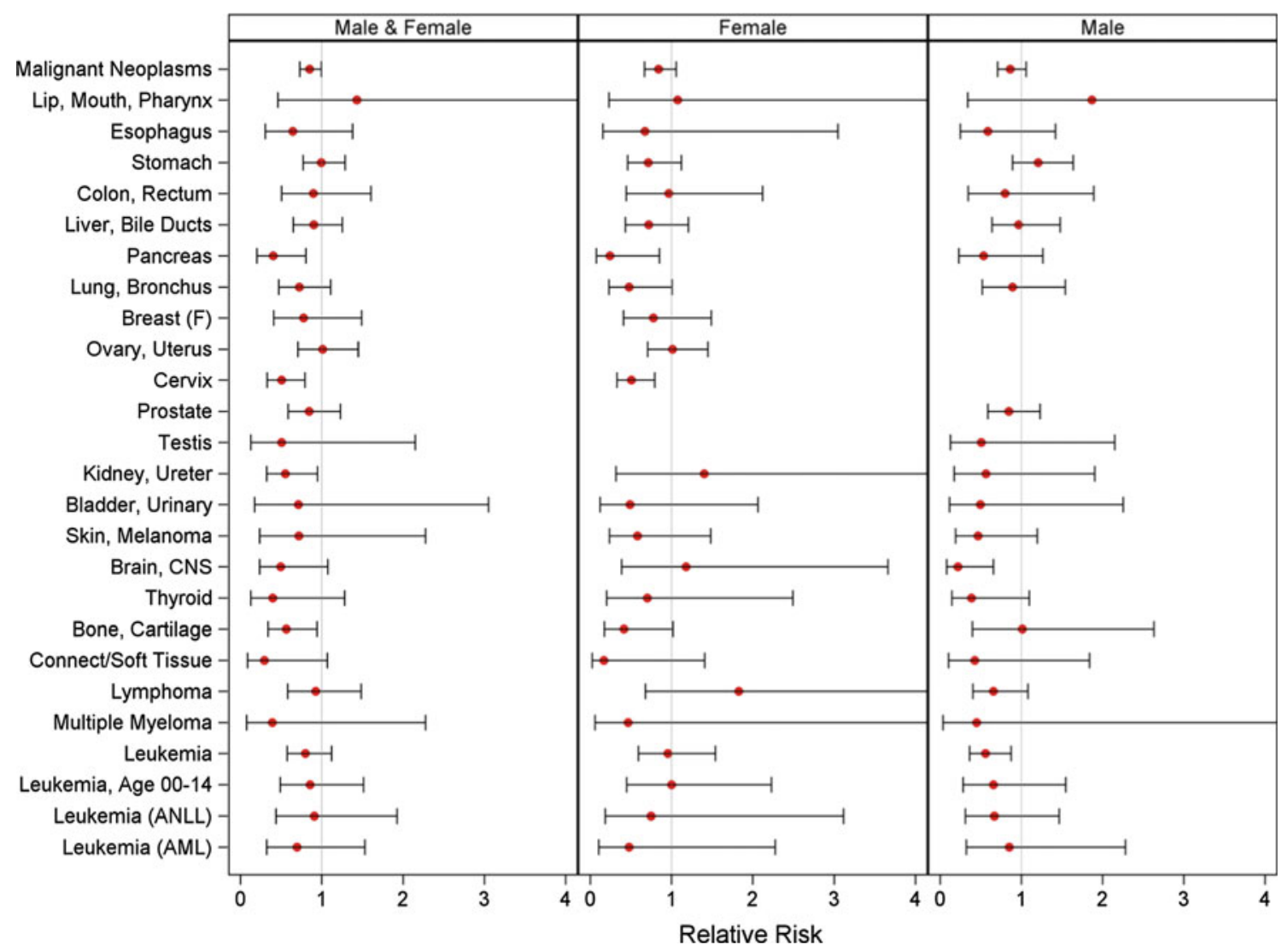

Fig. 2 Relative risks (RRs) for all cancer and cancer-specific death comparing seven oil-producing with 13 non-oil-producing cantons, 1990-2010

induction period revealed no consistent positive associations with overall or site-specific cancer mortality (data not shown).

\section{Discussion}

In this ecologic study, we found no evidence of increased overall or site-specific cancer mortality in association with increased level of oil exploration and production activities in the Oriente region of Ecuador. Whether oil-related activity was classified broadly or more finely based on well-years or volume of oil produced, and whether using the traditional SMR approach or the more flexible and detailed Poisson regression approach, we observed no apparent excess of cancer mortality in cantons with more oil exploration and production.

On the contrary, for several cancer sites, mortality was markedly lower in oil-producing than non-oil-producing cantons. If oil-producing cantons have more complete and accurate reporting of cause of death than non-oil-producing cantons due to greater access to mainstream health services as a result of oil-related economic activity, then differential outcome classification would be likely to result in overestimated-not underestimated-RRs. Given that the proportion of death certificates signed by a physician was similar between oil-producing $(65 \%)$ and non-oil-producing ( $58 \%$ ) cantons, and census measures of access to health care were also comparable between regions, it is improbable that information bias due to poorer vital statistics reporting in oil-producing than non-oil-producing cantons accounts for the absence of an observed association with cancer mortality. Instead, another plausible explanation for the observed deficits of cause-specific mortality in oil-producing cantons may be unmeasured differences in behavioral, social, cultural, and/or structural factors, rather than a direct beneficial effect of oil-related activities. This explanation is consistent with the fact that most associations were weaker in magnitude after adjustment for canton-level education attainment, indigenous fraction, and density of health care facilities.

Information potentially relevant to the evaluation of the health effects of crude oil exposure can be derived from occupational health studies of oil exploration and production workers. To our knowledge, five cohort studies (each with multiple publications) [14-19] and five case-control studies [6, 20-23] have evaluated cause-specific mortality and/or cancer incidence among oil exploration and 


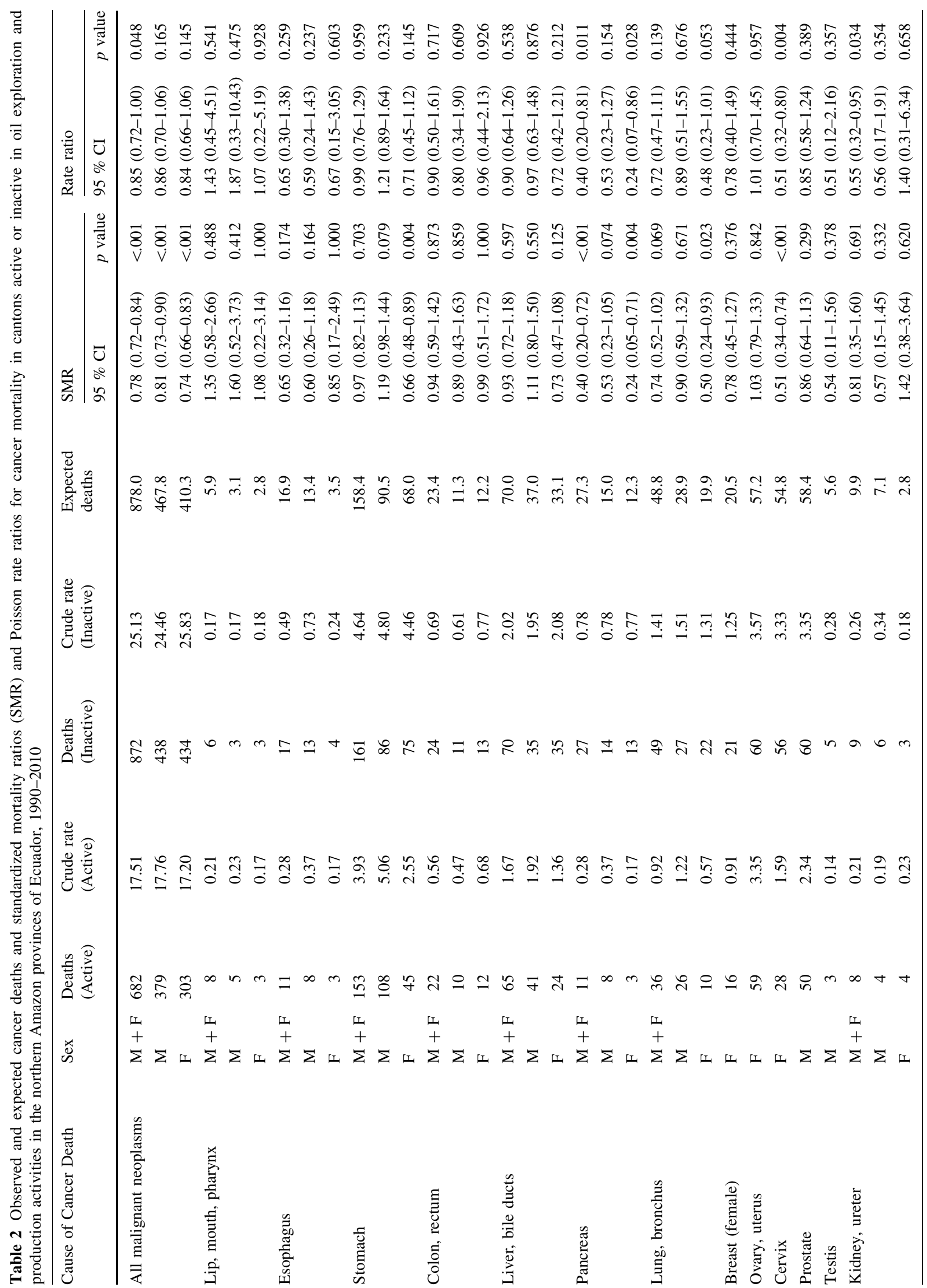




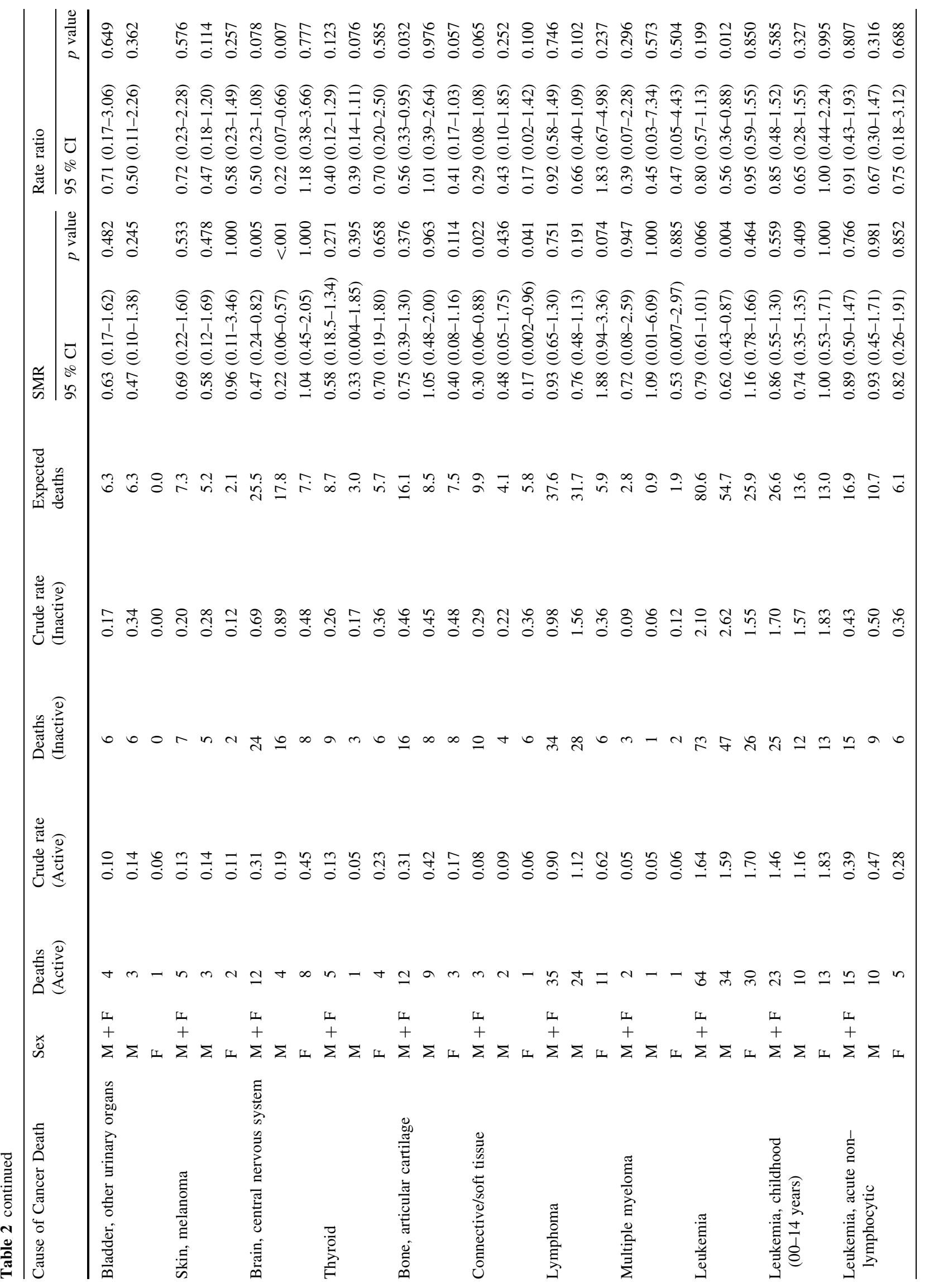




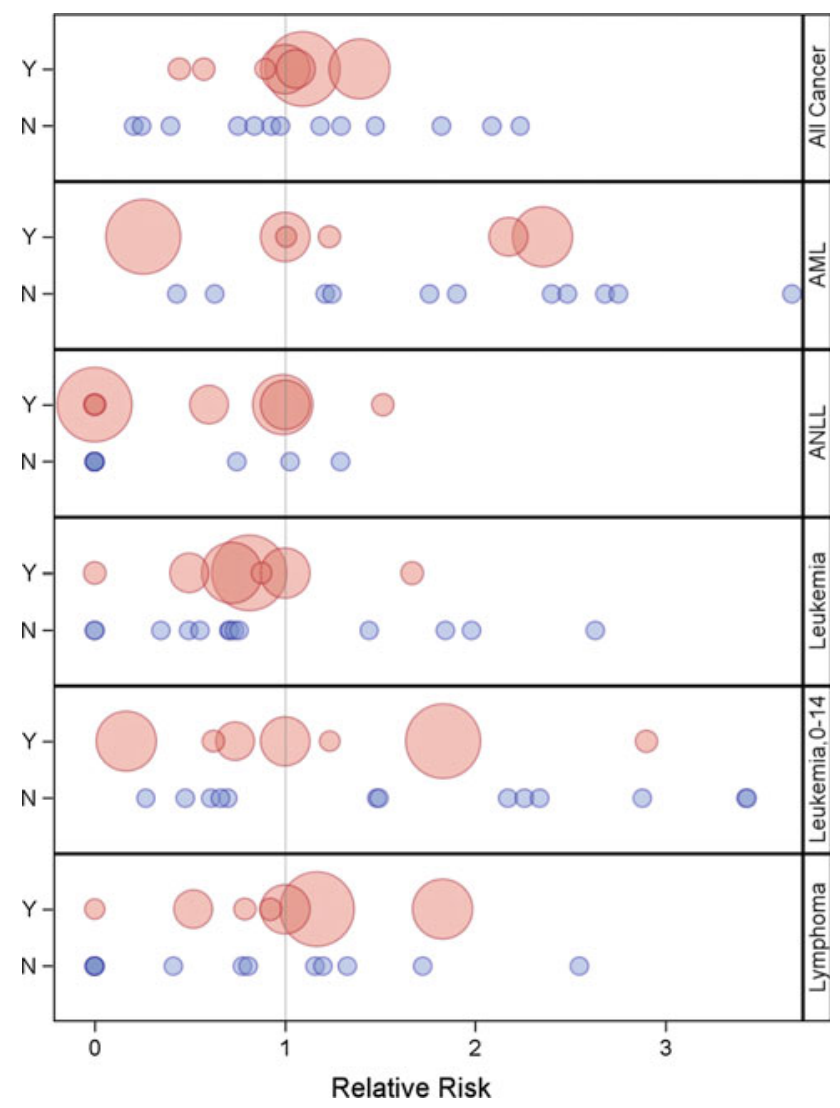

Fig. 3 Relative risk of all cancer and leukemia-related death in the seven cantons with oil exploration and production activity (shown in red; "Y" = yes, oil-producing) and thirteen cantons with little or no oil exploration and production activity (shown in blue; "N" = no, not oil-producing) in northern Amazon provinces in Ecuador, 1990-2010. The size of each red circle is proportional to the cumulative volume of oil produced as of 1990. AML = acute myeloid leukemia; ANLL = acute non-lymphocytic leukemia; leukemia, 0-14 = leukemia in children aged $0-14$ years. (Color figure online)

production (i.e., "upstream") workers. Overall, no clear picture of excess risk of cancer incidence or mortality has emerged from these studies, and no cancers occurred in significant excess in the majority of studies.

Kelsh et al. [4] found that liver cancer mortality in the Ecuadorian Amazon region in 1990-2005 was elevated in cantons with oil production activities. None of the occupational studies described above detected an excess of liver cancer incidence or mortality among upstream petroleum industry workers, nor did we detect such an excess in our updated analysis. Hepatitis B virus (HBV), the cause of the majority of liver cancer worldwide [24], is endemic in the Amazon basin, where $2-14 \%$ of the population is chronically infected, with differences in the prevalence of chronic infection by ethnicity and geographic region $[25$, 26]. Thus, chronic HBV infection may be a major determinant of regional differences in liver cancer incidence and mortality in the Amazon region of Ecuador. 
Fig. 4 Scatterplots of relative risk for overall and site-specific cancer mortality versus cumulative well-years (per $1,000)$ and oil produced (per 100 million barrels) as of 1990 , 2000, and 2010, with nonparametric Loess regression lines. $\mathrm{AML}=$ acute myeloid leukemia; ANLL = acute nonlymphocytic leukemia; leuk, $0-14=$ leukemia in children aged $0-14$ years

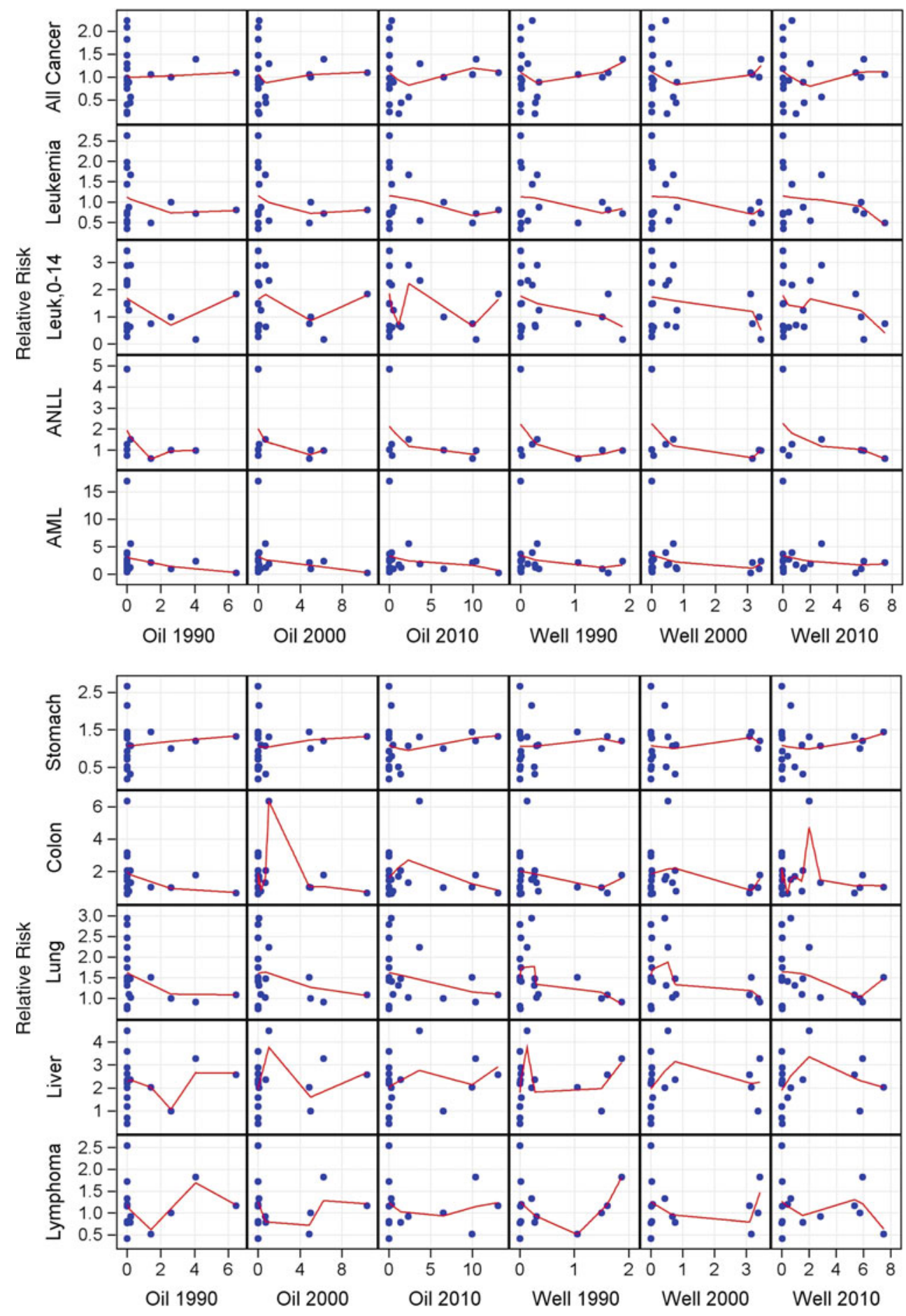

In the study by Hurtig and San Sebastián [2], the two malignancies that accounted for the greatest proportion of the excess overall cancer risk were stomach cancer in men and cervical cancer in women. Neither of these malignancies was consistently positively associated with oilrelated activities in our study, the study by Kelsh et al. [4], or the occupational studies of upstream petroleum industry workers described above. The primary causes of these cancers are also infectious agents, namely Helicobacter pylori as the leading cause of stomach cancer (and a minority of lymphomas), and oncogenic human papillomaviruses (HPV) as the leading cause of cervical cancer (and a substantial proportion of anogenital and oropharyngeal cancers) [24]. Both of these infections are common worldwide, including in Ecuador [27, 28]. The prevalence of $H$. pylori infection varies by individual- and area-level 
Table 3 Associations of age- and sex-adjusted canton-specific log-relative risks of cancer mortality with barrels of oil produced or well-years in 1990, adjusted for canton-level educational attainment, percent indigenous, and health care facilities per capita, northern Amazon provinces of Ecuador, 1990-2010

\begin{tabular}{|c|c|c|c|c|}
\hline \multirow[t]{2}{*}{ Cause of Death } & \multicolumn{2}{|c|}{ Oil Production (per 100 million barrels) } & \multicolumn{2}{|c|}{ Well-Years (per 1,000) } \\
\hline & Estimate $(95 \% \mathrm{CI})$ & $p$ value & Estimate $(95 \% \mathrm{CI})$ & $p$ value \\
\hline All malignant neoplasms & $1.04(0.74,1.45)$ & 0.807 & $1.07(0.40,2.86)$ & 0.889 \\
\hline Lip, mouth, pharynx & $0.94(0.56,1.57)$ & 0.788 & $4.09(0.90,18.60)$ & 0.066 \\
\hline Esophagus & $0.82(0.48,1.40)$ & 0.446 & $2.54(0.52,12.28)$ & 0.226 \\
\hline Stomach & $0.99(0.66,1.46)$ & 0.943 & $1.22(0.38,3.90)$ & 0.721 \\
\hline Colon, rectum & $0.87(0.57,1.31)$ & 0.475 & $1.35(0.40,4.58)$ & 0.602 \\
\hline Liver, bile ducts & $1.10(0.69,1.75)$ & 0.654 & $1.08(0.28,4.23)$ & 0.903 \\
\hline Pancreas & $1.15(0.83,1.60)$ & 0.383 & $0.35(0.13,0.93)$ & 0.038 \\
\hline Lung, bronchus & $0.96(0.75,1.23)$ & 0.735 & $0.93(0.46,1.91)$ & 0.841 \\
\hline Breast (female) & $1.08(0.71,1.66)$ & 0.698 & $0.74(0.21,2.60)$ & 0.616 \\
\hline Ovary, uterus & $0.87(0.56,1.35)$ & 0.518 & $1.84(0.51,6.65)$ & 0.328 \\
\hline Cervix & $0.93(0.73,1.18)$ & 0.506 & $1.33(0.59,2.96)$ & 0.433 \\
\hline Prostate & $0.98(0.65,1.47)$ & 0.904 & $1.13(0.34,3.74)$ & 0.831 \\
\hline Testis & $0.75(0.42,1.37)$ & 0.325 & $0.87(0.15,4.98)$ & 0.864 \\
\hline Kidney, ureter & $0.93(0.40,2.20)$ & 0.845 & $0.84(0.03,26.63)$ & 0.904 \\
\hline Bladder, other urinary organs & $0.94(0.61,1.46)$ & 0.776 & $0.52(0.14,1.90)$ & 0.299 \\
\hline Skin, melanoma & $1.38(0.01,351.13)$ & 0.827 & $3.51(0.00,-.-)$ & 0.824 \\
\hline Brain, central nervous system & $0.92(0.48,1.77)$ & 0.759 & $1.23(0.11,13.39)$ & 0.836 \\
\hline Thyroid & $0.95(0.62,1.45)$ & 0.806 & $0.47(0.13,1.61)$ & 0.209 \\
\hline Bone, articular cartilage & $1.06(0.72,1.56)$ & 0.736 & $0.53(0.17,1.66)$ & 0.255 \\
\hline Connective/soft tissue &.-- & &.-- & \\
\hline Lymphoma & $1.12(0.75,1.67)$ & 0.547 & $0.79(0.21,2.93)$ & 0.690 \\
\hline Multiple myeloma & $1.01(0.63,1.61)$ & 0.968 & $0.37(0.09,1.45)$ & 0.140 \\
\hline Leukemia & $1.01(0.77,1.33)$ & 0.917 & $0.71(0.30,1.63)$ & 0.381 \\
\hline Leukemia, childhood (00-14 y) & $1.24(0.77,1.98)$ & 0.352 & $0.32(0.08,1.29)$ & 0.102 \\
\hline Leukemia, acute non-lymphocytic & $1.54(0.20,12.06)$ & 0.459 & $0.26(0.00,25.75)$ & 0.335 \\
\hline Leukemia, acute myeloid & $0.60(0.35,1.04)$ & 0.066 & $2.14(0.43,10.60)$ & 0.323 \\
\hline
\end{tabular}

Educational attainment: proportion of canton residents aged 25 years and older educated at the high school level or above

CI: confidence interval

socioeconomic status, urbanization, sanitation, water quality, health care access, ethnicity, and birthplace [29, 30], while the prevalence of HPV infection varies by sexual behavior, which in turn depends on population migration and social, cultural, religious, and economic factors [31]. Any of these determinants could explain the observed geographic differences in stomach and cervical cancer incidence in the Ecuadorian Amazon region. Furthermore, disparities in cervical cancer incidence and mortality in Latin American countries have been attributed to differential access to cervical cancer screening and treatment [32].

The other findings of Hurtig and San Sebastián [2, 3], including excesses of incident cancers of the rectum, connective/soft tissue, kidney, uterine cervix, and lymph nodes and childhood leukemia, were not confirmed by our study or most studies of oil exploration and production workers. However, Yang and Zhang [33] observed an excess of leukemia around oil fields in China, and Gazdek et al. [34] reported a significant excess of certain hematopoietic malignancies, albeit not lymphomas or all leukemias combined, in Croatian populations living near oil and natural gas fields.

A key methodological difference that may explain part of the inconsistency in results across studies is our use of cancer mortality rather than incidence data. Hurtig and San Sebastián [2, 3], Yang and Zhang [33], and Gazdek et al. [34] used cancer incidence data, which more accurately reflect the risk of developing disease than cancer mortality data, especially for cancer types with relatively high survival. However, in regions that lack mandatory populationbased cancer surveillance, incident cases may be missed and those that are reported may represent a biased sample of total incident cases. For example, Hurtig and San 
Sebastián were able to include only incident cancer cases diagnosed in Quito and reported to the National Tumor Registry with a permanent residence in the Amazon region $[2,3,35]$. Suspected cancer cases in the Amazon region are referred to the capitol city of Quito for diagnosis and treatment, but the long distance-requiring as much as a 12-hour bus ride-and cultural differences between the Amazon and Quito most likely pose a substantial barrier to many residents of the study area. Therefore, cancer incidence among residents of the Amazon region may be grossly underreported, and cancer cases identified in the National Tumor Registry may differ considerably from unreported cases in terms of disease characteristics, patient attributes, and exposures. For example, it is conceivable that cancer cases in oil-producing areas, compared with those in non-oil-producing areas, have better access to navigable roads and/or transportation, enabling them to travel to Quito for diagnosis and treatment and resulting in overestimated relative risks.

By contrast, our study used mortality data abstracted from death certificates. Mortality rate ratios are unbiased estimates of incidence rate ratios if the exposure of interest does not affect disease survival or reporting. Currently, no evidence shows that proximity to oil exploration and production activities influences cancer survival. Compared with cancer incidence data in the Ecuadorian Amazon region, mortality data are likely to be more complete and less systematically biased. However, the use of death certificate data, especially in developing regions, entails important limitations in data quality and population coverage. First, the accuracy of the recorded cause of death depends on the diagnostic abilities of the responsible medical facility and/or physician. Second, mortality data may be deficient due to incomplete coverage of the civil registration system, leading to under-registration of deaths by an estimated $13.5 \%$ [36] to $30 \%$ [37], and such underregistration may be unequal between oil-producing and non-oil-producing regions. Third, all death records had a cause of death listed, but $25 \%$ of deaths in oil-producing cantons and $28 \%$ in non-oil-producing cantons had "symptoms and ill-defined conditions" identified as the cause of death. Thus, misclassification of causes of death was undoubtedly present, with potential variation across cantons in accordance with degree of development, access to medical care, and other demographic and socioeconomic factors, leading to an unknown impact on the results.

Other differences between our analysis and those of Hurtig and San Sebastián include the definitions of areas with or without oil exploration and production, and methods for estimating the annual population at risk in the study area. We used information on well and oil field locations, drilling dates, and oil field production volumes to characterize the extent of oil exploration and production activities. By contrast, the sources and methods used by Hurtig and San Sebastián were not clearly specified and resulted in different classifications than ours [2, 3], although our results were similar when using their classification. We used data from the 1990, 2001, and 2010 national censuses and imputed canton-, age-, and sex-specific population denominators for each intercensal year. Hurtig and San Sebastián used population projections for 1992 or 1993, based on the 1990 national census, as denominators for cancer incidence rates in 1985-1998 or 1985-2000. The latter approach almost certainly underestimated post-1990 populations. Based on national census data showing that oil-producing populations grew more quickly than non-oil-producing populations between 1990 and 2001, this approach would have resulted in overestimated relative risks.

Our study and previous investigations of cancer in communities surrounding oil fields [2-4, 33-35, 38] are all limited by their ecologic design, in which exposure status is assigned at the community level. By assuming that all individuals within a given community have the same exposure status, such studies introduce an unknown degree and direction of bias, as associations observed at the community level may not apply at the individual level. Furthermore, ecologic studies such as these have limited information on potential confounders that may explain observed differences in disease rates between populations. Most studies, including ours, have modest numbers of most site-specific cancers, with correspondingly limited statistical power and ability to control for confounding. An additional concern is that none of these studies can account fully for residential migration and therefore could not classify individuals according to the canton in which they resided for the longest duration or at a biologically relevant latency period prior to death. In fact, biologically plausible latency periods between exposure to oil-related contaminants and cancer diagnosis or death are not established. Finally, we were unable to assess the validity and completeness of oil well and oil production data or cancer mortality data. Even if exposure and outcome misclassification were random, however, the resulting bias would not necessarily attenuate the estimated RRs [39-41]. Given these substantial limitations, the reported associations cannot be interpreted as definitively establishing or refuting a causal effect of crude oil on cancer incidence or mortality.

Ideally, studies of the association between residence near oil fields and risk of cancer should use individual-level data on exposure to crude oil and its waste products, as well as abundant data on potential confounders. However, no studies of environmental exposure to oil exploration and production activities have collected such information, and unbiased prospective collection of such data is now 
virtually impossible, in the aftermath of immense public scrutiny and controversy concerning oil exploration and production in the Ecuadorian Amazon region, along with close involvement of local organizations in setting the agenda of research in the region [42].

Despite these caveats, our study offers several advantages over previously published studies of health outcomes in the Ecuadorian Amazon region. These strengths include more years of follow-up, allowing for longer latency periods and larger sample sizes; more detailed, quantitative information on oil exploration and production; a more refined approach to data analysis; and adjustment for potential confounding by demographic and socioeconomic factors. In particular, a key advantage of the Poisson regression method over the more conventional SMR method is the ability to accommodate a multi-category or continuous rather than binary exposure variable.

In conclusion, in this extended and enhanced analysis of cancer mortality in the Oriente region of Ecuador from 1990 through 2010, we observed no apparent excess of death from any or all cancers in areas with oil exploration and production activities, compared with areas that had little or no oil-related activity. Given the methodological limitations of this study, our findings do not necessarily indicate that exposure to crude oil and oil-related activities is causally unrelated to any form of cancer. However, our findings provide no evidence to support such a relationship and further demonstrate that in the Ecuadorian Amazon region, residing near oil fields appears not to adversely affect cancer mortality.

Acknowledgments The authors appreciate the technical assistance provided by the Chevron Corporation in identifying oil fields and oil production data. The authors acknowledge Dr. Vanessa Perez and Ms. Lydia Ho from Exponent, Inc., for their assistance in researching the INEC data and preparing the analysis and the manuscript. All authors are employees of Exponent, Inc., an international consulting company. This work was done with financial support from the Chevron Corporation. Neither the Chevron Corporation nor any of its personnel was involved in the conduct of this study or the content of the manuscript.

Conflict of interest The authors do not declare any other competing interests.

Open Access This article is distributed under the terms of the Creative Commons Attribution License which permits any use, distribution, and reproduction in any medium, provided the original author(s) and the source are credited.

\section{References}

1. IARC (1989) IARC Monographs on the Evaluation of Carcinogenic Risks to Humans. Vol 45. Occupational exposures in petroleum refining; crude oil and major petroleum fuels. International Agency for Research on Cancer (IARC), Lyon
2. Hurtig AK, San Sebastián M (2002) Geographical differences in cancer incidence in the Amazon basin of Ecuador in relation to residence near oil fields. Int J Epidemiol 31(5):1021-1027

3. Hurtig AK, San Sebastián M (2004) Incidence of childhood leukemia and oil exploitation in the Amazon basin of Ecuador. Int J Occup Environ Health 10(3):245-250

4. Kelsh MA, Morimoto L, Lau E (2009) Cancer mortality and oil production in the Amazon Region of Ecuador, 1990-2005. Int Arch Occup Environ Health 82(3):381-395. doi:10.1007/s00420008-0345-X

5. Arana A, Arellano F (2007) Cancer incidence near oilfields in the Amazon basin of Ecuador revisited. Occup Environ Med 64(7):490

6. Siemiatycki J, Dewar R, Nadon L, Gerin M, Richardson L, Wacholder S (1987) Associations between several sites of cancer and twelve petroleum-derived liquids. Results from a case-referent study in Montreal. Scand J Work Environ Health 13(6):493-504

7. INEC (August 1994) Proyecciones de población por provincias, cantones, áreas, sexo y grupos de edad. Período 1990-2000. Instituto Nacional de Estadística y Censos (INEC), Quito

8. INEC (August 2004) Proyecciones de población por provincias, cantones, áreas, sexo y grupos de edad. Periodo 2001-2010. Instituto Nacional de Estadística y Censos (INEC), Quito

9. Petroecuador (various years) Informe Anual 1995, 1996, 1997, 1998, 1999, 2001, 2003. Gerencia de economía y finanzas, planificación corporativa de petroecuador (empresa estatal petroleos del Ecuador), Quito

10. Petroecuador (various years) Producción de crudo. In: Informe Estadístico 1972-2006, 2007, 2008, 2009, 2010. Gerencia de economía y finanzas, planificación corporativa de petroecuador (empresa estatal petroleos del Ecuador), Quito

11. Breslow NE, Day NE (1975) Indirect standardization and multiplicative models for rates, with reference to the age adjustment of cancer incidence and relative frequency data. $\mathrm{J}$ chronic Dis 28(5-6):289-303

12. Breslow NE, Day NE (eds) (1987) Statistical methods in cancer research. Vo II, The Design and analysis of cohort studies. IARC Scientific Publications No. 82. International Agency for Research on Cancer, Lyon

13. Rothman KJ, Boice JD Jr (1982) Epidemiologic Analysis with a Programmable Calculator, New edn. Epidemiology Resources Inc., Boston, MA

14. Divine BJ, Hartman CM (2000) Update of a study of crude oil production workers 1946-94. Occup Environ Med 57(6):411-417

15. Lewis RJ, Schnatter AR, Katz AM, Thompson FS, Murray N, Jorgensen G, Theriault G (2000) Updated mortality among diverse operating segments of a petroleum company. Occup Environ Med 57(9):595-604

16. Sim M, Glass D, Cui J, Del Monaco A, Giuliano K, Friesen M, Wood E (2007) Health Watch. The Australian Institute of Petroleum Health Surveillance Program. Thirteenth Report. Department of Epidemiology and Preventive Medicine, Monash Centre for Occupational and Environmental Health, Monash University, Australia

17. Kirkeleit J, Riise T, Bjorge T, Moen BE, Bratveit M, Christiani DC (2010) Increased risk of oesophageal adenocarcinoma among upstream petroleum workers. Occup Environ Med 67(5):335-340. doi:10.1136/oem.2009.046953

18. Huebner WW, Wojcik NC, Jorgensen G, Marcella SP, Nicolich MJ (2009) Mortality patterns and trends among 127,266 U.S.based men in a petroleum company: update 1979-2000. J Occup Environ Med/Am College of Occup Environ Med 51(11):1333-1348. doi:10.1097/JOM.0b013e3181be6c18

19. Huebner WW, Wojcik NC, Jorgensen G, Marcella SP, Nicolich MJ (2010) Mortality patterns and trends among 49,705 U.S.based women in a petroleum company: update 1979-2000. 
J Occup Environ Med/Am College Occup Environ Med 52(1):99-108. doi:10.1097/JOM.0b013e3181ca0db3

20. Atkinson S, Coppock J, Fritschi L, Glass D, Gibbons C, Gray CN, Ikin J, Jolley D, O'Keefe J, Sim M (2001) Lympho-haematopoietic cancer and exposure to benzene in the Australian petroleum industry. Technical report and appendices. Monash University and Deakin University, Australia

21. Gottlieb MS (1980) Lung cancer and the petroleum industry in Louisiana. Journal of occupational medicine: official publication of the Industrial Medical Association 22(6):384-388

22. Gottlieb MS, Pickle LW, Blot WJ, Fraumeni JF Jr (1979) Lung cancer in Louisiana: death certificate analysis. J Natl Cancer Inst 63(5):1131-1137

23. Sathiakumar N, Delzell E, Cole P, Brill I, Frisch J, Spivey G (1995) A case-control study of leukemia among petroleum workers. J Occup Environ Med/Am College Occup Environ Med 37(11):1269-1277

24. de Martel C, Ferlay J, Franceschi S, Vignat J, Bray F, Forman D, Plummer M (2012) Global burden of cancers attributable to infections in 2008: a review and synthetic analysis. Lancet Oncol 13(6):607-615. doi:10.1016/s1470-2045(12)70137-7

25. Manock SR, Kelley PM, Hyams KC, Douce R, Smalligan RD, Watts DM, Sharp TW, Casey JL, Gerin JL, Engle R, AlavaAlprecht A, Martinez CM, Bravo NB, Guevara AG, Russell KL, Mendoza W, Vimos C (2000) An outbreak of fulminant hepatitis delta in the Waorani, an indigenous people of the Amazon basin of Ecuador. Am J Trop Med Hyg 63(3-4):209-213

26. Weinbaum CM, Williams I, Mast EE, Wang SA, Finelli L, Wasley A, Neitzel SM, Ward JW (2008) Recommendations for identification and public health management of persons with chronic hepatitis B virus infection. MMWR Recommendations and reports : Morbidity and mortality weekly report Recommendations and reports/Centers for Disease Control 57 (RR-8):1-20

27. Gomez NA, Salvador A, Vargas PE, Zapatier JA, Alvarez J (2004) Seroprevalence of Helicobacter pylori among the child population of Ecuador. Rev Gastroenterol Peru: Organo oficial Soc Gastroenterol Peru 24(3):230-233

28. Tornesello ML, Buonaguro L, Izzo S, Lopez G, Vega X, Maldonado Reyes CF, Buonaguro FM (2008) A pilot study on the distribution of human papillomavirus genotypes and HPV-16 variants in cervical neoplastic lesions from Ecuadorian women. J Med Virol 80(11):1959-1965. doi:10.1002/jmv.21317

29. Bruce MG, Maaroos HI (2008) Epidemiology of Helicobacter pylori infection. Helicobacter 13(Suppl 1):1-6. doi:10.1111/j. 1523-5378.2008.00631.x

30. Ford AC, Axon AT (2010) Epidemiology of Helicobacter pylori infection and public health implications. Helicobacter 15(Suppl 1):1-6. doi:10.1111/j.1523-5378.2010.00779.x
31. Bosch FX, Burchell AN, Schiffman M, Giuliano AR, de Sanjose S, Bruni L, Tortolero-Luna G, Kjaer SK, Munoz N (2008) Epidemiology and natural history of human papillomavirus infections and type-specific implications in cervical neoplasia. Vaccine 26(Suppl 10):K1-16. doi:10.1016/j.vaccine.2008.05.064

32. Villa LL (2012) Cervical Cancer in Latin America and the Caribbean: the problem and the way to solutions. Cancer Epidemiol Biomark Prev 21(9):1409-1413. doi:10.1158/1055-9965. epi-12-0147

33. Yang C, Zhang X (1991) Incidence survey of leukemia in China. Chin Med Sci J chung-kuo i hsueh k'o hsueh tsa chih/Chin Acad Med Sci 6(2):65-70

34. Gazdek D, Strnad M, Mustajbegovic J, Nemet-Lojan Z (2007) Lymphohematopoietic malignancies and oil exploitation in Koprivnica-Krizevci County, Croatia. Int J Occup Environ Health 13(3):258-267

35. San Sebastián M, Hurtig AK (2004) Cancer among indigenous people in the Amazon Basin of Ecuador, 1985-2000, Pan Am J Pub Health 16(5):328-333

36. Merino C, Aguinaga L, Vallejo F (1997) Correction of underregistration of general mortality. Correo poblacional y de la salud/Centro de Estudios de Poblacion y Paternidad Respon $5(3): 15-19$

37. Mathers CD, Fat DM, Inoue M, Rao C, Lopez AD (2005) Counting the dead and what they died from: an assessment of the global status of cause of death data. Bull World Health Organ 83(3):171-177. doi:/S0042-96862005000300009

38. San Sebastián M, Armstrong B, Córdoba JA, Stephens C (2001) Exposures and cancer incidence near oil fields in the Amazon basin of Ecuador. Occup Environ Med 58(8):517-522

39. Jurek AM, Greenland S, Maldonado G, Church TR (2005) Proper interpretation of non-differential misclassification effects: expectations vs observations. Int J Epidemiol 34(3):680-687. doi:10. 1093/ije/dyi060

40. Thomas DC (1995) Re: when will nondifferential misclassification of an exposure preserve the direction of a trend?". Am J Epidemiol 142(7):782-784

41. Weinberg CR, Unbach DM, Greenland S (1995) Weinberg et al. reply [Letter]. Am J Epidemiol 142:784

42. San Sebastián M, Hurtig AK (2005) Oil development and health in the Amazon basin of Ecuador: the popular epidemiology process. Social science \&amp; medicine (1982) 60 (4):799-807. doi:10.1016/j.socscimed.2004.06.016 